\title{
Characterization of Biodiesel by Unconventional Methods: Photothermal Techniques
}

\author{
Maria Castro, Francisco Machado, Aline Rocha, Victor Perez, \\ André Guimarães, Marcelo Sthel, Edson Corrêa and Helion Vargas \\ State University of the North Fluminense Darcy Ribeiro (UENF)
}

Brazil

\section{Introduction}

Atmospheric Pollution is one of the most concerning problems of modern society. The pollution of air can cause local and global impacts (Rockstrom et al., 2009, Steffen et al., 2003), modifying the climate (Hansen et al., 2008, Rosenzweig et al., 2008, Solomon et al., 2009), damaging the human healthy and the environment, have at the moment an international prominence. The Intergovernmental Panel on Climate Change (IPCC) report (IPCC, 2007a, 2007b) concluded that emissions of greenhouse effect gases (GEE) has increased due to anthropic actions resulting a rise of the Earth's average temperature. An alternative to minimize these effects is the use of renewable sources, as an attempt to reduce global warming (Meinshausen et al., 2009, Allen et al., 2009).

However, access to energy underpins our current way of life and promotes hopes among peoples around the world for improved lives. Mobility is a core component of these aspirations, as transport has become the main factor in increasing global primary oil demand, and is expected to grow by $1.3 \%$ per year up to 2030, reaching 116 million barrels a day (Meinshausen \& Meinshausen, 2009) (from 84 million barrels per day in 2005). The transport sector in particular relies almost entirely on oil, which is to become increasingly scarce and costly in the next few decades, and supplies may be prone to interruption. Biofuels (Bauen et al., 2008, Tilman et al., 2006) - fuels derived from plant materials - have the potential to address these two issues. At first sight they appear to be carbon neutral, renewable (fresh supplies can be grown as needed) and can be cultivated in many different environments. In addition they are an integral part of the emerging 'bio-economy', where plant material is used to produce specific chemicals and bulk industrial chemicals. In the future biofuels may increasingly replace chemicals derived from fossil fuel. The full picture, however, is much more complex as different biofuels have widely differing environmental, social and economic impacts. The predicted shortage of fossil fuel has encouraged the search for substitutes for petroleum derivatives. This search resulted in an alternative fuel called "biodiesel".

Biodiesel obtained from different vegetable oils is considered to be as an attractive option. From environmental standpoint, biodiesel is carbon neutral since all carbon dioxide released during consumption is sequestered from the atmosphere for growth of vegetables oil crops. The other environmental advantages in using biodiesel are: it is easy to use, as well as being biodegradable, non-toxic, reduces emissions of particulate, 
reduces emissions of carbon dioxide, its emissions causes $50 \%$ less ozone to form than conventional diesel fuel, and it is essentially free of sulfur and aromatics (Ragauskas et al., 2006). According to the Brazilian Biodiesel Program, biodiesel is defined as a biodegradable fuel derived from renewable sources such as vegetable oils and animal fats. Technically speaking, biodiesel is the alkyl ester of fatty acids, produced by chemical or enzymatic transesterification of vegetal oils or animal fats with short-chain alcohol such as methanol and ethanol (Barnwal \& Sharma, 2005). Glycerin is consequently a by-product from biodiesel production (Pinto et al., 2005, Schuchardt et al., 1998). In addition, the flash point of biodiesel (around $150^{\circ} \mathrm{C}$ ), being significantly higher than that petroleum diesel (around $50^{\circ} \mathrm{C}$ ), is much safer for transportation than petroleum diesel. Vegetable biodiesel can be obtained from different sources, as soybean, sunflower, castor bean, cotton, African oil palm (Elaeis guianensis), babassu palm, animal fats or simply oil of domestic fry. In addition, biodiesel can be a total or partial substitute for petroleum diesel to diesel engines through preparation of blends diesel/ biodiesel with different proportions. Thus, petrodiesel blended with $2 \%, 5 \%, 10 \%$ and $20 \%$ of biodiesel are known as B2, B5, B10 and B20, respectively, up to pure biodiesel (B100).

As a consequence of the fast increasing use of biodiesel one of the major concerns is the lack of standardization and certification of the products purity. Any remaining reactants from the extraction procedure can induce changes in the physicochemical properties, which may result in erosion or failure of the fuel injection components of the diesel engine. A promising area of studies to characterize this biomaterial is the measurement of the thermal properties. Thermal properties reveal important information on the physicochemical processes in the material and may certainly be an additional route to characterize biodiesel oils (Demirbas, 2003). Therefore, the use of non-conventional and advantageous methods to measure the biodiesel thermal properties appears to be relevant. Photothermal methods include a wide range techniques and phenomena which are based on the conversion of absorbed optical energy into heat.

Since the middle of the 1970's, photothermal techniques have proved to be a powerful tool to investigate physical properties of materials, with multiple branches of application. In the beginning these techniques were devoted to spectroscopic studies, especially in nonconventional systems, such as highly light diffusive and opaque materials, biological samples, etc (Rosencwaig, 1973; Cesar et al., 1979). Further applications were directed to the thermal characterization of solid, gaseous, pasty and liquid materials. Studies of diverse systems are reported in literature, such as semiconductors, conductive polymers, optical fibers, ceramics, foodstuff, non-electrolytic and ionic liquids, as well as magnetic and organic materials (Guimarães et al., 2009; Vargas \& Miranda, 1988; Almond \& Patel, 1996). The photothermal techniques are based on the detection of very small temperature variations produced by the absorption of radiation. The periodic or transient heating generates thermal waves, and their detection can provide information about thermal and optical properties of materials. There are many techniques for detecting such thermal diffusion waves, and the choice for each one is determined by taking into account the specificity of the sample being investigated and the kind of study to be performed.

Among the photothermal techniques, two of them are very suitable for the characterization of liquid samples, which are The Thermal Lens (TL) and Photopyroelectric (PPE) techniques. In the thermal lens experiments, an excitation laser beam, with a Gaussian profile intensity, crosses the sample to be investigated. A portion of energy is absorbed and its conversion into heat generates a radial temperature profile into the sample, which consequently gives 
rise to a refraction index profile. The temporal evolution of such thermal lens is strictly related to optical and thermal properties of the sample and is detected by a probe beam, which impinges in a photodiode after passes through the sample (Shen et al., 1992). In the photopyroelectric technique, the thermal waves are produced by the absorption of radiation with modulated intensity and detected by a pyroelectric transducer, which is a polymeric or ceramic material, in contact with the sample. The temperature oscillations in the pyroelectric sensor induce changes in the dielectric polarization charge over its electrodes, which are detected as an ac electric voltage or current signal by a lock-in analyzer (Coufal, 1984).

Recently, both the Thermal Lens and the photoacoustic techniques have proved to be useful for the characterization of biodiesel. Using thermal lens, it was possible to measure the thermal diffusivity and the temperature coefficient of refraction index of biodiesel samples obtained from distinct precursor oils, using both ethanol and methanol for the transesterification processes (Castro et al., 2005). Furthermore, it was applied to soybean biodiesel samples in order to evaluate the influence of residues and antioxidants on its thermo-optical properties (Lima et al., 2009). The photopyroelectric was used to the complete thermal characterization of biodiesel, meaning the determination of the thermal diffusivity, effusivity, conductivity and the heat capacity per unit volume (Guimarães et al., 2009).

\section{Photothermal methodology}

The conduction of heat, for a stationary temperature regime, can be described by the Fourier's Law, which relates the temperature gradient and the heat flux density, with the thermal conductivity being the proportionality factor (Carslaw \& Jaeger, 1959). Nevertheless, the photothermal approach is based on the detection of thermal waves, i.e., it involves time dependent distribution of temperature. In this case, the local energy conservation is necessary in order to write the heat diffusion equation, given by:

$$
\nabla^{2} T(\vec{r}, t)-\frac{1}{\alpha} \frac{\partial T}{\partial t}(\vec{r}, t)+\frac{s(\vec{r}, t)}{k}=0
$$

The term $s(\vec{r}, t)$ represents the heat sources distribution and the thermal diffusivity, $\alpha$, is the relevant transport parameter. It is defined in terms of the thermal conductivity $(k)$, density $(\rho)$ and specific heat (c) as $\alpha=\mathrm{k} / \rho c$ (Almond \& Patel, 1996). The thermal diffusivity $(\alpha)$ reveals how fast the heat flows in a given material, since it simultaneously depends on the way how the heat is conducted (dependence with $\mathrm{k}$ ) and absorbed (dependence with $\rho$ ).

The photothermal measurements usually deal with the propagation of thermal waves in layered systems. Thus, the mathematical approach consists in writing the heat diffusion equations (1) for all the media involved, and so coupling them by imposing boundary conditions, such as temperature and heat flux continuity at the interfaces. This procedure gives rise to another important parameter, the reflection coefficient of the thermal wave between two adjacent media, given by

$$
R_{i j}=\left(b_{i j}-1\right) /\left(b_{i j}+1\right)
$$

where $b_{i j}=e_{i} / e_{j}$ is the ratio of the thermal effusivities of these media. The thermal effusivity and the thermal diffusivity are defined in terms of the thermal conductivity $(\mathrm{k})$, density $(\rho)$ and specific heat (c) as $e=(\rho c k)^{1 / 2}$ (Almond \& Patel, 1996). This property is essential for 
describing the behavior of heat flux, when going through different media, as it plays an important role in the detection of thermal wave.

In general, the photothermal techniques allow the measurement of thermal diffusivity and effusivity. The thermal conductivity and the heat capacity per unit volume are thus indirectly determined, by inverting the expressions written above. In some special cases, depending on the sample thickness and the photothermal configuration used, it is possible to obtain directly the thermal conductivity or the specific heat (Glorieux et al., 1995; Menon et al., 2009). The thermal properties can be measured by photothermal techniques from experiments presenting good reproducibility, with uncertainties being around $1-5 \%$. It is important to stress that such of liquid samples are not easily investigated with conventional methods, mainly because of convection currents caused by great stationary temperature gradients. In photothermal devices, the temperature oscillations generated by the laser beam absorption are quite small, as commented above, suppressing the convection effects and also avoiding changes in the sample's properties during the measurements.

\subsection{Photopyroelectric technique}

The photopyroelectric (PPE) detection was introduced in the eighties (1984), as a powerful tool for a measurement of thermal properties of materials (Coufal, 1984, Mandelis, 1984, Dadarlat et al., 1984). Many studies with edible oils, foodstuff, molecular associations in binary liquids, fatty acids and automotive fuels have been reported in the recent past (Coufal, 1984, Nockemann et.al, 2009, Bicanic et al., 1992, Longuemart et al., 2002, Dardalat \& Neamtu, 2006, Dadarlat et al., 1995, Cardoso et al., 2001). Although this technique is most suitable for liquid and pasty systems, it can also be applied for solid samples, if a good care is taken concerning the sample-sensor coupling (Mandelis \& Zver, 1985, Salazar, 2003).

This technique is based on the use of a pyroelectric transducer to convert thermal waves to an ac electric voltage or ac current signal via induced changes in the dielectric polarization charge over the transducer electrodes. The pyroelectric response $S(t)$ of the detector due to a periodic (frequency $f$ ) temperature variation is given by equation 3 (Chirtoc \& Miháilescu, 1989):

$$
S(t)=\frac{i 2 \pi f \tau_{p} p L_{p}}{\mathrm{~K}_{p}\left(1+i 2 \pi f \tau_{p}\right)} \theta_{p}(f) e^{i 2 \pi f t}
$$

where $\tau_{p}=R C$ is the electrical time constant, considered the equivalent resistance-capacitance circuit, and $p, L_{p}$ and $K_{p}$ are the pyroelectric coefficient, the thickness and the dielectric constant of the pyroelectric sensor, respectively. The term $\theta_{p}(f)$ is the spatially averaged temperature field over the sensor thickness, which is obtained by solving the coupled onedimensional heat diffusion equations. For simplicity, the pyroelectric response can be written as:

$$
S(t)=A(f) \Gamma(f) e^{i 2 \pi f t}
$$

$A(f)$ is considered a transfer function, it represents the global frequency response of the used electric circuitry that converts the oscillating temperature into the ac voltage or current signal that is synchronously detected by the lock-in analyzer. In general, the detection of the pyroelectric signal is performed using current mode, which reduces the resistive and capacitive influences of sensor and cables (Chirtoc et al., 2003). $\Gamma(f)$ is a dimensionless 
response factor containing relevant information about the thermal properties and thickness of the different layers, among which is the sample layer of interest.

The two main PPE configurations for thermal characterization of liquid samples are called standard (SPPE) and inverse (IPPE) configurations. In the so called standard photopyroelectric (SPPE) configuration, the incident light is absorbed at the sample's surface and the thermal wave reaches the sensor in contact with the other sample's surface, allowing the determination of the thermal diffusivity $(\alpha)$.

For the SPPE configuration, the one-dimensional heat diffusion is considered in a four-layer system, constituted by air (g), sample (s), pyroelectric sensor (p) and backing (b). Since the interest here is getting information about thermal properties, a very thin cooper foil is used in the gas-sample interface, in order to guarantee the superficial absorption of the incident radiation. Besides the opaque sample assumption, it is considered that the thermal waves are completely attenuated in the gas and backing layers. Thus, the general form of $\Gamma(f)$ (Chirtoc \& Miháilescu, 1989) is reduced to the following expression:

$$
\Gamma(f)=\frac{2\left(b_{g p}+1\right)}{\left(b_{g s}+1\right)\left(b_{s p}+1\right)} e^{-\sigma_{s} L_{s}} P(f)
$$

where $P(f)$ can be considered as a perturbation factor that becomes effective only at low frequency. If the frequency is high enough to consider sample and sensor as thermally thick $\left(\mu_{s}<L_{s}, \mu_{s}>L_{s}\right)$, the perturbation factor is $P(f)=1$ (Delencos et al., 2002), where:

$$
\mu_{s}=\sqrt{\alpha_{s} / \pi f}
$$

is the thermal diffusion length. Then, amplitude and phase of $\Gamma(f)$ can be written as:

$$
\begin{gathered}
|\Gamma(f)|=\frac{2\left(b_{g p}+1\right)}{\left(b_{g s}+1\right)\left(b_{s p}+1\right)} e^{-\frac{L_{s}}{\mu_{s}}} \\
\varphi(f)=-\frac{L_{s}}{\mu_{s}}
\end{gathered}
$$

One can notice that both amplitude and phase explicitly depend on the sample thickness and implicitly depend on the modulation frequency $(f)$ besides the sample's thermal diffusivity, via $\mu_{s}=(\alpha / \pi f)^{1 / 2}$. Moreover, $\ln |\Gamma(f)|$ as well as $\varphi(f)$ present a linear dependence with $(f)^{1 / 2}$, and both curves have the same slope $S_{\text {freq. }}$. This behavior allows the determination of the sample's thermal diffusivity, from amplitude and phase, by performing frequency scan measurements, knowing the sample's thickness $L_{s}$ :

$$
\alpha_{s}=\frac{\pi L_{s}^{2}}{S_{\text {freq }}^{2}}
$$

Since the term $A(f)$ in equation (4) also plays a role in a frequency scan, a calibration measurement is necessary in order to guarantee that the fitting data contains only information about the sample. In a different approach, the sample's thermal diffusivity is determined by performing thickness scan, with the modulation frequency kept constant. 
The dependence of both $\ln |\Gamma(f)|$ and $\varphi(f)$ with the sample's thickness is linear, with the curves having the same slope $S_{\text {thick. }}$. In this case the thermal diffusivity is determined by

$$
\alpha_{s}=\frac{\pi f}{S_{\text {thick }}^{2}}
$$

As presented above, the standard SPPE configuration allows one to determine the thermal diffusivity of materials from two different ways. In recent studies the thickness scan approach has been adopted, in which thickness specific values do not play a hole, being important the values variation. Moreover, in such approach no calibration is necessary in order to cancel the transfer function $A(f)$. Typical relative errors using thickness scan are around 0.8-3 \% (Dadarlat \& Neamtu, 2009a, Balderaz-López \& Mandelis, 2002, Dadarlat \& Neamtu, 2009b)

The inverse IPPE configuration is similar to the standard one, but the modulated light beam reaches first the sensor, and the thermal wave is completely attenuated in the sample. Thus, we can consider almost the same schematic layer-system of SPPE, just replacing " $\mathrm{s}$ " by " $\mathrm{p}$ " and neglecting the " $\mathrm{b}$ " layer. With these assumptions, the general form of $\Gamma(f)$ is reduced to (Dadarlat \& Neamtu, 2009a):

$$
\Gamma(f)=\frac{1-e^{-\sigma_{p} L_{p}}+R_{s p}\left(e^{-2 \sigma_{p} L_{p}}-e^{-\sigma_{p} L_{p}}\right)}{\left(b_{g p}+1\right)\left(1-R_{g p} R_{s p} e^{-2 \sigma_{p} L_{p}}\right)}
$$

Considering the extreme and opposite thermal effusivities of air and sensor, one can find $b_{s p}=0$ and $R_{s p}=-1$, and the equation (10) is simplified. From this point, we can choose for two different approaches, depending on the relation between the sensor thermal diffusion lenght and thickness.

For the first approach, the frequency is low enough to assume that the sensor is very thermally thin and the sample very thermally thick, then the amplitude of $\Gamma(f)$ becomes (Pittois et al., 2001):

$$
|\Gamma(f)|=\frac{\sqrt{\pi f} L_{p} c_{p}}{e_{s}}
$$

while the phase assumes the constant value of $-\pi / 4$. Thus it has reached a special case that allows the determination of the thermal effusivity of the sample. Besides the dependence with sensor properties, the IPPE signal amplitude also depends on the transfer function $A(f)$. In order to eliminate these contributions and get the sample's effusivity $e_{S}$, the experiments consists in normalizing the signal amplitude of the sample to some reference material, with known effusivity $e_{\text {ref. }}$ This normalized signal $S_{n}$ is given by:

$$
S_{n}=\frac{e_{r e f}}{e_{s}}
$$

Such method was widely used in the nineties; the experimental errors are around 1-10\% (Dadarlat et al., 1990, 1996 and 1997) mainly related to instabilities on the laser intensity.

For the second approach, the frequency is high enough to assume that the sensor is thermally thick and the sample very thermally thick. For this configuration, thicker sensors 
are better to manipulate and the information is obtained from the phase data, avoiding those laser instabilities (Longuemart et al., 2002).

Moreover, the pyroelectric signal for the sample must be normalized by the signal for the empty cell, i. e., the sample being air. With these assumptions, the normalized $\Gamma_{n}(f)$ is given by (Sahraoui \& Longuemart, 2002):

$$
\Gamma_{n}(f)=1-\left(1+R_{s p}\right) e^{-\sigma_{p} L_{p}}
$$

and its phase can be written as:

$$
\tan \varphi=\frac{\left(1+R_{s p}\right) \sin \left(L_{p} / \mu_{p}\right) e^{-L_{p} / \mu_{p}}}{1-\left(1+R_{s p}\right) \cos \left(L_{p} / \mu_{p}\right) e^{-L_{p} / \mu_{p}}}
$$

It depends on the modulation frequency, properties of the sensor and the reflection coefficient $R_{s p}$, which carries information about the sample's effusivity. The inversion of equation (14) leads to:

$$
R_{s p}=\frac{\tan \varphi e^{L_{p} / \mu_{p}}}{\sin \left(L_{p} / \mu_{p}\right)+\cos \left(L_{p} / \mu_{p}\right) \tan \varphi}-1
$$

The normalized phase is an oscillating function, which passes through 0 (zero) when $\mathrm{L}_{\mathrm{p}} / \mu_{\mathrm{p}}=$ $\mathrm{n} \pi$, with $n=1,2,3 \ldots$ Thus, performing a frequency scan, this parameter can be obtained from the signal phase and used in equation (15) in order to get $R_{s p}$. This equation is not mathematically defined for $\varphi=0$, but one can choose a frequency range where $R_{s p}$ is constant and get and average value for that. Knowing the sensor effusivity $e_{p}$, one can obtain the sample's effusivity $e_{s}$ from:

$$
e_{s}=\frac{\left(1+R_{s p}\right)}{\left(1-R_{s p}\right)} e_{p}
$$

The reported errors for this approach are around 1-3 \% (Longuemart et al., 2002, Dadarlat \& Neamtu, 2006, Dadarlat et al., 2009).

\subsection{Thermal lens technique}

The Thermal Lens effect was first observed by Gordon et al., when transient power and beam divergence alters the output of Helium-Neon laser, after placing transparent samples in a laser cavity (Gordon et al., 1964, 1965). Thermal Lens Spectrometry (TLS) is one of a family of photothermal techniques that can be used to measure spectroscopy and thermooptical properties of transparent materials (Cruz et al., 2011, Franko 2002, Sampaio et al., 2002, Bialkowski, 1996, Shen et al., 1992, Baesso et al., 1994). This technique has proved to be high sensitive and accurate, it is approximately three orders more sensitive than conventional transmission methods. The Thermal Lens effect was created when the sample is exposed to an excitation laser beam with a Gaussian intensity profile. A fraction of absorbed energy is converted into heat, generating a radial temperature profile $T(r, t)$. As a result of this local temperature increase a lens-like optical element in the heated region is created. There are many experimental configurations of Thermal Lens (Gordon et al., 1965, 
$\mathrm{Hu}$ et al., 1973). Nowadays the dual beam mode-mismatched configuration is the most widely used because of its high sensitivity (Baesso et al., 1994). In the figure 1 we present an schematic figure for a typical beam configuration of dual beam mode-mismatched configuration. This arrangement consists of two lasers beams with a different spot sizes in the sample position.

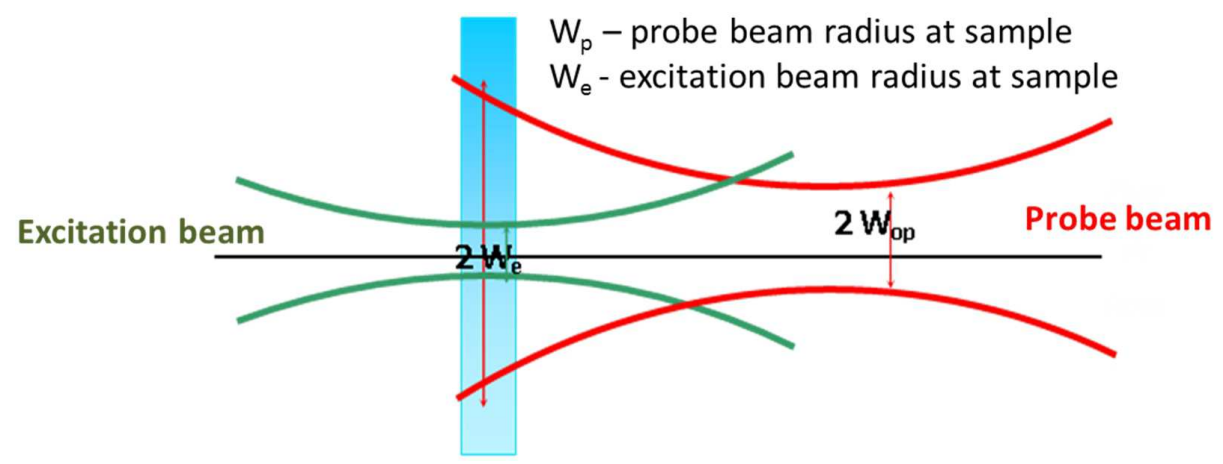

Fig. 1. Schematic diagram of dual beam mode-mismatched configuration, where $\mathrm{w}_{\mathrm{p}}$ and $\mathrm{w}_{\mathrm{e}}$ are, respectively, the probe and excitation beam radius at the sample

The presence of such thermal lens is detected by its effect on the propagation of a probing beam passing through the sample. The temporal evolution of the on-axis probe beam intensity, $\mathrm{I}(\mathrm{t})$, is measured in the far field using a circular aperture in front of a photodiode. Shen et al. using the Fresnel diffraction theory, determined an analytical expression for the probe beam intensity at the detector (Shen et al., 1992):

$$
I(t)=I(0)\left[1-\frac{\theta}{2} \tan ^{-1}\left(\frac{2 m V}{\left[(1+2 m)^{2}+V^{2}\right]\left(t_{c} / 2 t\right)+1+2 m+V^{2}}\right)\right]^{2}
$$

where

$$
m=\left(\frac{\omega_{p}}{\omega_{e}}\right)^{2}
$$

$w_{p}$ and $w_{e}$ are, respectively, the probe and excitation beam radius at the sample, $V=z_{1} / z_{c}, z_{1}$ is the distance between the sample and probe beam waist, and

$$
z_{c}=\pi \omega_{0}^{2} / \lambda_{p}
$$

is the probe beam Rayleigh range, $\omega_{0}$ is the minimum probe beam radius, $\lambda_{\mathrm{p}}$ is the probe beam wavelength, $I(0)$ is the value of $I(t)$ when the transient time $t$ or the phase shift, $h$, is zero. The TL transient signal amplitude is proportional to its phase shift, $h$, given by :

$$
\theta=-\frac{P_{e} A L}{k \lambda_{p}}\left(\frac{d n}{d T}\right)_{p}
$$


in which $P_{e}$ is the excitation laser power, $k$ is the thermal conductivity, $(d n / d T)_{p}$ is the temperature coefficient of refractive index at the probe beam wavelength, $A_{e}$ is the optical absorption coefficient at the excitation beam wavelength, $L_{e f f}=\left(1-\exp \left(-A_{e} L\right)\right) / A_{e}$ is the effective length and $L$ is the sample thickness. The TL temporal signal evolution depends on the characteristic thermal time constant, $t_{c}$, which is given by (Baesso, 1994)

$$
t_{c}=w_{e}^{2} / 4 \alpha
$$

\section{Potentialities of photothermal methods on biodiesel characterization}

In order to explain the potentialities of Photothermal Methods in the Biodiesel characterization, a set of thermal properties studies using Thermal Lens and Photopyroelectric techniques have been done. Thus, the section 3.1 presents a complete characterization of thermal properties of Biodiesel using only PPE technique. In the section 3.2 we present a complete characterization of thermal properties of Biodiesel using both techniques.

\subsection{Thermal properties of biodiesel using photopyroelectric technique}

We first show the results for the SPPE configuration, related to thickness scan measurements in order to obtain thermal diffusivity. Water and ethylene glycol were chosen as reference samples to calibrate the cell (Guimarães et al., 2009).

For the photopyroelectric technique. the experimental arrangement is schematically shown in Fig. 2. For the standard (SPPE) configuration (2a), the pyroelectric sensor used was a PVDF (polyvinylidenedifluoride) foil, with $110 \mu \mathrm{m}$ thickness and around $1 \mathrm{~cm}^{2}$ area. The sample is hold by a cooper cylinder, glued to the sensor with silicone. An aluminum mask provides both the superficial absorption ( $80 \mu \mathrm{m} \mathrm{Cu}$ foil on the bottom) and the sample's thickness control, by means of an attached micrometer. The radiation source was an $80 \mathrm{~mW}$ argon laser (514 nm), chopped by an acoustic-optical modulator. Measurements were performed at a fixed frequency $(3 \mathrm{~Hz})$, scanning the sample's thickness from 600 to $200 \mu \mathrm{m}$, with a $20 \mu \mathrm{m}$ step. The data acquisition was done as function of time, with the values of amplitude and phase of the signal being averaged for each thickness. For the inverse (IPPE) configuration (2b), two different sensors were used, a PVDF with $9 \mu \mathrm{m}$ thickness, for the thermally thin sensor approach, and PZT (lead-titanium-zirconate) ceramic, with $210 \mu \mathrm{m}$,

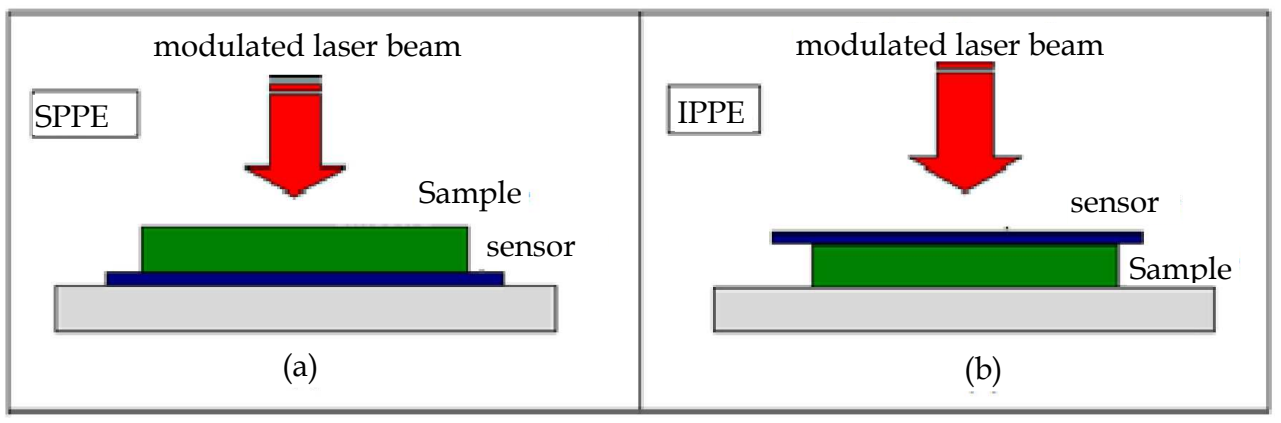

Fig. 2. Schematic figure for $t$ he SPPE (a) and IPPE (b) setups. 
for the thermally thick sensor approach. For both sensors, the surface which absorbs the laser beam was black inked. The sample is hold as in SPPE, but in this case having around 5 $\mathrm{mm}$ thickness, fulfilling the sample's thermally thick condition. The radiation source was a $15 \mathrm{~mW}$ diodo laser, electronically self modulated. In all the setups, the pyroelectric signal was measured by a SR830 lock-in analyzer, using the current mode detection.

The complete data analysis is presented for a Canola (Brassica napus) biodiesel, as an example, and the diffusivity values for the whole set of samples are in Table 3. As expected, the amplitude seams to decrease exponentially with the sample's thickness, while the phase presents a linear behavior (Eq. 7). For each thickness this signal is averaged and the results for the natural logarithm of amplitude and phase versus sample's thickness are shown in Fig. 3. The signal has a good stability, with a signal-tonoise ratio of 500, at the minimum. It is clear the accordance of both amplitude and phase with the predicted behavior in (Eq. 7).

With these data, according to Eq. 9, we calculate the thermal diffusivity from both amplitude $\left(\alpha_{a m p l}\right)$ and phase ( $\left.\alpha_{\text {phase }}\right)$ of the signal. The data fitting present a good regression coefficient, which is confirmed by the small uncertainties in the diffusivity values (Fig. 3), around $0.5 \%$. Nevertheless, many repetitions were performed, which allowed us to check the very good reproducibility of the experiments, and determine a medium value for the thermal diffusivity of the samples Canola (Brassica napus) biodiesel (Table 1). The statistical error, considering the many repetitions, is more realistic, around $1 \%$, and it was also observed for all the samples, as it can be seen in (Table 1). The obtained thermal diffusivity values for water and ethylene glycol is in very good agreement with data reported in literature (Dadarlat \& Neamtu, 2006, Delencos et al., 2002, Balderáz-Lopes et al., 2000, Bindhu et al., 1998). It is not easy to compare the results for the biodiesel samples, since their thermal properties are strictly related to the manufacturing and storage processes. However, we can notice that the thermal diffusivity present good precisions and assume values similar to results obtained for other biodiesel samples (Castro et al., 2005).

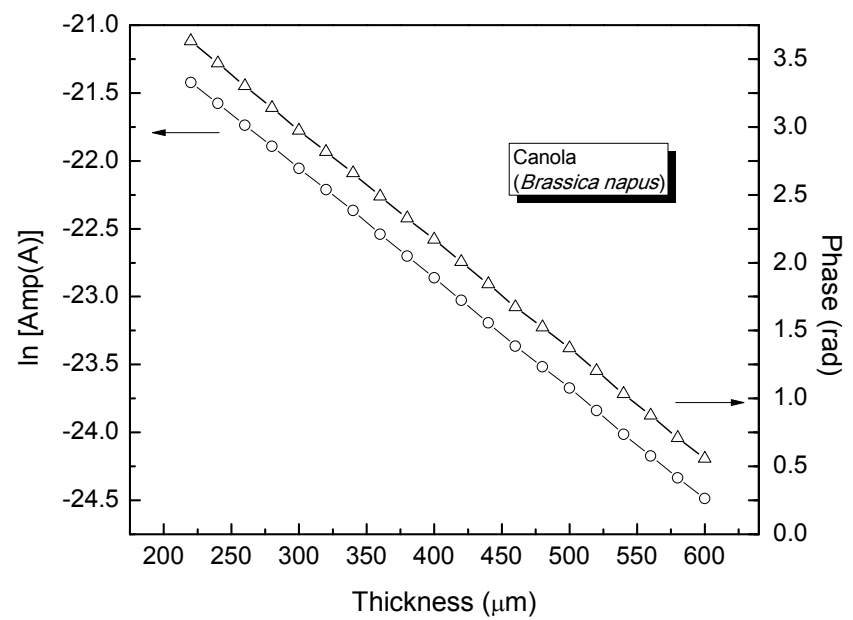

Fig. 3. Natural logarithm of amplitude and phase for SPPE signal as function of the sample's thickness. 
The thermal effusivity determination, in any way, depends on a reference material, with known thermal effusivity. In this work we chose Ethylene Glycol as the standard, assuming an averaged value (Dadarlat \& Neamtu, 2006, Delencos et al., 2002, Sahraoui et al., 2002, Menon et al., 2009), $810\left(W_{s}^{1 / 2} m^{-2} K^{-1}\right)$. We first present the results for the thermally thin sensor approach, in which the thermal effusivity is obtained from the signal amplitude. The measurements were performed using frequencies from 0.01 to $2 \mathrm{~Hz}$. For this frequency range, the normalized signal was averaged and calculations based on Eq. 12 lead to the thermal effusivity determination for water, macaw, canola, pequi (Caryocar brasiliense) and babassu (Table 1). In addition, the Figure 4 shows the normalized amplitude as a function of modulation frequency for the canola (Brassica napus) biodiesel. The results for water and the biodiesel samples are in good agreement with other reported data (Dadarlat \& Neamtu, 2006, Delencos et al., 2002, Castro et al., 2005, Balderaz-López \& Mandelis, 2003) and present reasonable experimental errors, between $2-5 \%$, considering the sensibility of the signal amplitude with fluctuations in the sensor response.

Concerning the thermally thick approach, the modulation frequency was scanned in the 1-70 $\mathrm{Hz}$ range. Measurements were performed for water, ethylene glycol and tree biodiesel samples. The results for normalized phase versus frequency are shown in Fig. 5.

As expected, all the curves cross the abscissa zero point at the same frequency, since it depends only on properties of the sensor. Thus, using the thickness of the sensor, we obtain get its thermal diffusivity, $\alpha_{p}=(4.82 \pm 0.08) \times 10^{-7} \mathrm{~m}^{2} / \mathrm{s}$. This value is used as an initial point for the data fitting which leads to the $R_{s p}$ evaluation (Eq. 15). Knowing the average value of $R_{s p}$ we can determine the thermal effusivity (Eq. 16). From the curve for Ethylene Glycol we get the thermal effusivity of the sensor, $e_{p}=(1940 \pm 20) W s^{1 / 2} m^{-2} K^{-1}$, and this value is used to determine the thermal effusivity of the other samples. The measurements were repeated for all samples, and the results, shown in Table 1, present better precisions (0.6-2 \%) compared to the values obtained from the signal amplitude.

Considering the values of thermal diffusivity, obtained from SPPE configuration, and effusivity, obtained from IPPE, we could determine the thermal conductivity of all the investigated materials, using the relation $k=e(\alpha)^{1 / 2}$, and these results are also presented in

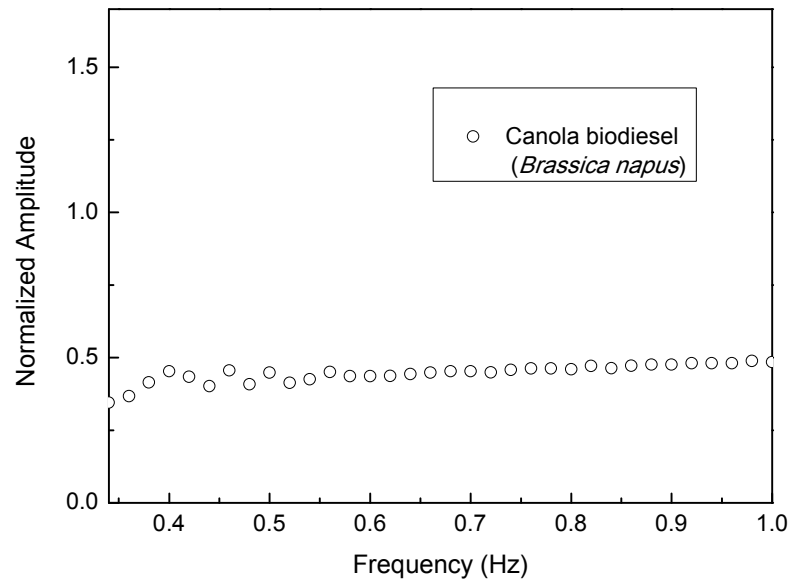

Fig. 4. Normalized amplitude as function of modulation frequency 


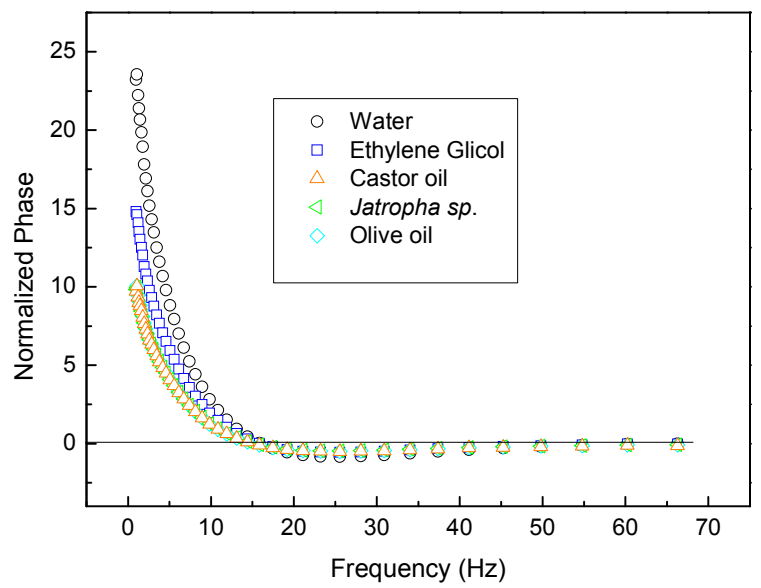

Fig. 5. Frequency scans of the normalized phase for various liquid samples, using the IPPE setup with the thermally thick sensor approach.

\begin{tabular}{|c|c|c|c|c|}
\hline \multirow[t]{2}{*}{ Biodiesel } & \multirow[t]{2}{*}{$\begin{array}{c}\text { *Thermal } \\
\text { Diffusivity } \times 10^{7} \\
\left(\mathrm{~m}^{2} / \mathrm{s}\right)\end{array}$} & \multicolumn{2}{|c|}{$\begin{array}{c}\text { *Thermal } \\
\text { Effusivity } \\
\left(\mathbf{W ~ s} \mathbf{s}^{1 / 2} \mathbf{m}^{-2} \mathrm{~K}^{-1}\right)\end{array}$} & \multirow[t]{2}{*}{$\begin{array}{c}{ }^{*} \text { Thermal } \\
\text { Conductivity } \\
(\mathrm{W} / \mathrm{mK})\end{array}$} \\
\hline & & IPPE & SPPE & \\
\hline $\begin{array}{l}\text { Canola } \\
\text { (Brassica napus) }\end{array}$ & $0.860 \pm 0.010$ & $516 \pm 11$ & - & $0.153 \pm 0.008$ \\
\hline $\begin{array}{l}\text { Macaw } \\
\text { (Acrocomia aculeate) }\end{array}$ & $0.820 \pm 0.010$ & $522 \pm 27$ & - & $0.148 \pm 0.003$ \\
\hline $\begin{array}{l}\text { Olive oil } \\
\text { (Olea europaea L.) }\end{array}$ & $0.840 \pm 0.010$ & - & $505 \pm 3$ & $0.146 \pm 0.002$ \\
\hline $\begin{array}{l}\text { Castor oil } \\
\text { (Ricinus communis L.) }\end{array}$ & $0.790 \pm 0.007$ & - & $532 \pm 5$ & $0.150 \pm 0.002$ \\
\hline $\begin{array}{l}\text { Pinhão Manso } \\
\text { (Jatropha curcas) }\end{array}$ & $0.882 \pm 0.007$ & - & $530 \pm 6$ & $0.157 \pm 0.002$ \\
\hline $\begin{array}{l}\text { Babaçu } \\
\text { (Orbignya phalerata) }\end{array}$ & - & $556 \pm 16$ & - & - \\
\hline $\begin{array}{l}\text { Pequi } \\
\text { (Caryocar brasiliense) }\end{array}$ & - & $562 \pm 15$ & - & - \\
\hline
\end{tabular}

*Thermal diffusivity, effusivity, conductivity were estimated by Eqs. $(10,17,21)$ and $k=e \sqrt{\alpha}$, respectively.

Table 1. Thermal Properties of all the Investigated Samples

Table 1 The uncertainties are quite small, around 1-2 \%, except for Canola, which is close to $5 \%$, certainly due to the error in the effusivity measurement.

According to attained results may be considered that photopyroelectric methodology allows the investigation of thermal properties of liquid and pasty materials. In this work we have 
shown specific applications to the characterization of biodiesel. With the technique, thermal diffusivity and effusivity can be obtained from different configurations (SPPE and IPPE) and the thermal conductivity can thus be calculated. Experiments present a good reproducibility, with uncertainties less than $5 \%$ and the setups are relatively simple.

\subsection{Thermal properties of biodiesel using thermal lens and photopyroeletric techniques}

The samples analyzed in this study were obtained by transesterification of macaw palm, canola oil, pequi and babassu oils using ethanol. The first technique used to determine the thermal diffusivity of biodiesel was the Thermal Lens. The Thermal Lens measurements were performed in the dual beam mode-mismatched configuration, the Fig. 6 shows the schematic diagram of the experimental set-up for thermal diffusivity measurements. $\mathrm{An}^{-} \mathrm{Ar}^{+}$ ion laser (Coehrent innova 300C) was used as excitation beam at 488nm and either an He-Ne laser was used as probe beam at $632,8 \mathrm{~nm}$. The samples were placed in a quartz cuvette $(\mathrm{L}=2 \mathrm{~mm})$. The samples were positioned at the waist of excitation beam; in Table 2 we present the experimental parameters used in the experimental set-up.

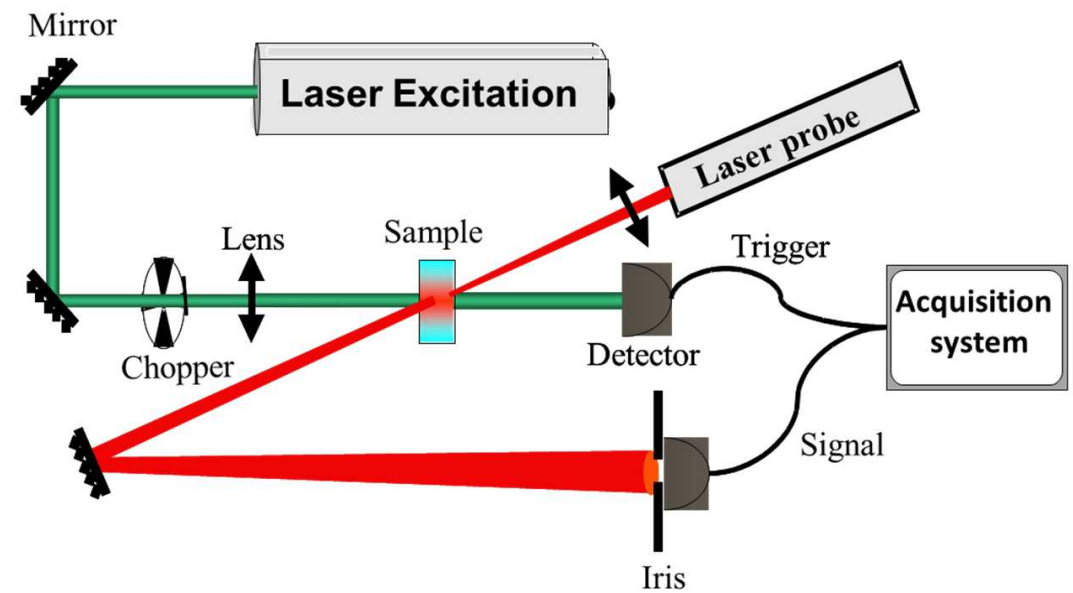

Fig. 6. Experimental set-up $T L$ technique

\begin{tabular}{|c|c|c|c|c|c|c|}
\hline Laser & $\begin{array}{c}\text { Beam } \\
\text { Wavelength } \\
\left(\times 10^{-9} \mathrm{~m}\right)\end{array}$ & $\begin{array}{c}\text { Probe Beam } \\
\text { Rayleigh Range } \\
(\mathrm{cm})\end{array}$ & $\begin{array}{l}\text { Minimum } \\
\text { Probe Radius } \\
\left(\times 10^{-3} \mathrm{~cm}\right)\end{array}$ & $\begin{array}{l}\text { Ratio of } \\
\text { beam } \\
\text { waists in } \\
\text { the sample }\end{array}$ & $\begin{array}{c}\text { Ratio } \\
\text { distances }\end{array}$ & $\begin{array}{c}\text { Excitation } \\
\text { laser spot } \\
\text { size at the } \\
\text { sample } \\
\left(\times 10^{-3} \mathrm{~cm}\right)\end{array}$ \\
\hline & - & & & & & - \\
\hline $\mathrm{He}-\mathrm{Ne}$ & 632.8 & 5.23 & 10.27 & - & - & - \\
\hline $\mathrm{Ar}$ & 488.0 & 0.63 & 3.14 & 43.68 & 1.76 & 3.12 \\
\hline
\end{tabular}

Table 2. Experimental parameters

In the transient Thermal Lens measurements, the parameters $\theta$ and $t_{c}$ are determined directly by fitting the experimentally observed time profile of developing Thermal Lens 
effect to Figure 7 shows a normalized time resolved Thermal Lens signal obtained for canola sample, where excitation beam power was $30 \mathrm{~mW}$. From the curve fitting using the equation (17), we obtained $\theta=0.10005 \pm 0.00007$ and $\alpha=1.090 \pm 0.005 \times 10^{-3} \mathrm{~cm}^{-2} / \mathrm{s}$.

We used the same procedure in order to determine the thermal diffusivity for other samples and the results are shown in the Table 2. The effusivity measurements were obtained using the Photopyrolectric technique with the IPPE configuration, in the section 3.1 we were present the details. The results of thermal conductivity can be determined using the relation $\alpha=k / \rho c$. The values obtained are in agreement with the results from literature (Castro et al. 2005, Lima et al. 2009).

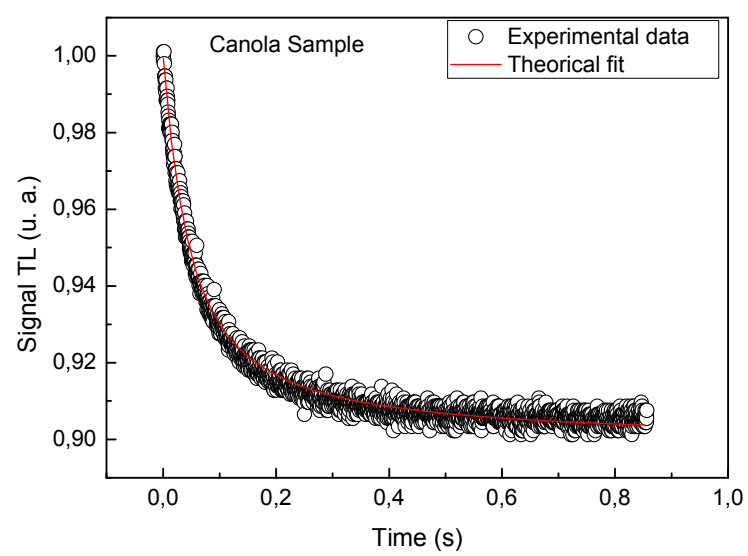

Fig. 7. TL transient signal for canola oil sample (circle) and the excitation beam power was $30 \mathrm{~mW}$.

\begin{tabular}{lccc}
\hline Biodiesel & $\begin{array}{c}\text { Thermal } \\
\text { Diffusivity } \\
\left(10^{7} \mathrm{~m}^{2} / \mathrm{s}\right)\end{array}$ & $\begin{array}{c}\text { Thermal } \\
\text { Effusivity } \\
\left(\mathrm{Ws} \mathrm{s}^{1 / 2} \mathrm{~m}^{-2} \mathrm{~K}^{-1}\right)\end{array}$ & $\begin{array}{c}\text { Thermal } \\
\text { Conductivity } \\
(\mathrm{W} / \mathrm{mK})\end{array}$ \\
\hline $\begin{array}{l}\text { Sunflower } \\
\text { (Helianthus annus) }\end{array}$ & $1.090 \pm 0.009$ & $534 \pm 9$ & $0.176 \pm 0.004$ \\
$\begin{array}{l}\text { Macaw } \\
\text { (Acrocomia aculeate) }\end{array}$ & $1.160 \pm 0.009$ & $522 \pm 10$ & $0.177 \pm 0.001$ \\
$\begin{array}{l}\text { Babassu } \\
\text { (Orbignya phalerata) }\end{array}$ & $1.120 \pm 0.007$ & $556 \pm 16$ & $0.186 \pm 0.001$ \\
$\begin{array}{l}\text { Canola } \\
\text { (Brassica Napus) }\end{array}$ & $1.100 \pm 0.005$ & $516 \pm 16$ & $0.171 \pm 0.004$ \\
$\begin{array}{l}\text { Pequi } \\
\text { (Caryocar brasiliense) }\end{array}$ & $1.200 \pm 0.009$ & $562 \pm 15$ & $0.195 \pm 0.002$ \\
\hline
\end{tabular}

Table 3. Thermal Properties of all the investigated Samples 
Several factors, such as presence air, light, heat (high temperature), light traces of metal, antioxidants, peroxides as well as the nature of the storage containers can trigger oxidative processes, thus will be altered the quality of biodiesel (Knothe et al., 2005). The physical properties of biodiesel are strictly related to kind of fatty acid present in their composition and consequently the autoxidation is due to the presence of double bonds in the chains in the unsaturated fatty acids. Therefore, the properties such as viscosivity, density and thermal diffusivity are a function of the temperature and fatty acids composition, among other parameters. Thus, thought an analysis of these properties it is possible to verify of the biodiesel quality. In the sections 3.1 and 3.2 we presented the thermal characterization of biodiesel from several sources using the Thermal Lens and Photopyrolectric techniques, respectively, and the attained results showed differences between calculated thermal diffusivity values, e.g., for the macaw oil was obtained thermal diffusivity values of $1.16 \times 10^{-}$ $7 \mathrm{~m}^{2} / \mathrm{s}$ by TL method, in despite of $0.86 \times 10^{-7} \mathrm{~m}^{2} / \mathrm{s}$ by PPE technique. This variation may be related to oxidative processes because the thermal diffusivity measurements between the TL and PPE were carried out to set at the intervals of 15 months, approximately. Similar results were observed by Lima et al. 2009 and Castro et al., (2005) which observed a reduction in the thermal diffusivities in oxidated samples.

On the other hand, a inversely exponential correlation between the thermal diffusivity and iodine value (IV) for biodiesel produced from several oils source was observed (Fig. 8) reveling that thermal diffusivity for each biodiesel is a function from fatty acid composition, essentially for unsaturated compound. Further studies should be carried out to verify this behavior for other oils whose composition is preferentially of saturated fatty acids.

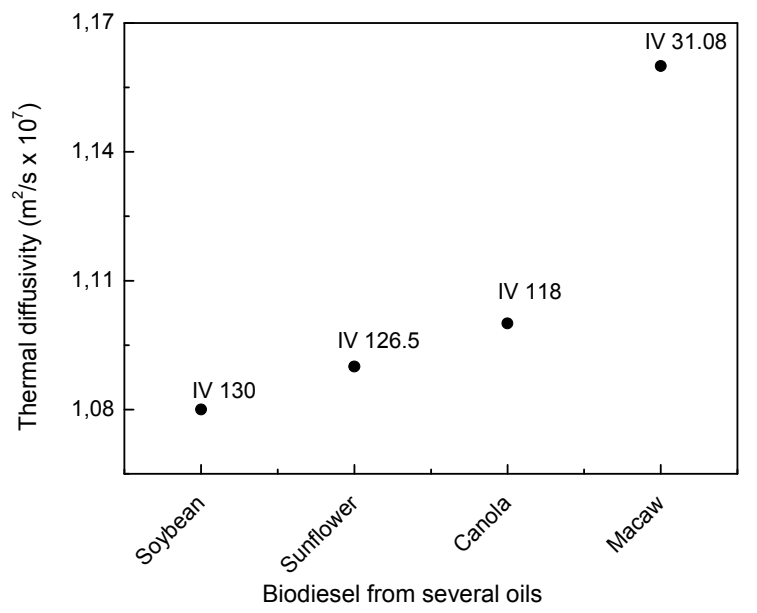

Fig. 8. Correlation between the thermal diffusivity and iodine value (IV) for biodiesel produced from several oils source.

\section{Acknowledgements}

The authors want to thank to The State of Rio de Janeiro Research Foundation (FAPERJ) and the National Council for Scientific and Technological Development (CNPq) for financial 
support. Also, thank to Prof. Dr. Donato Aranda goes providing kindly the biodiesel samples used in this work.

\section{References}

Allen, M. R.; Frame, D. J.; Huntingford, C.; Jones, C. D.; Lowe, J. A.; Meinshausen, M. and Meinshausen, N. (2009) Warning Caused by Cumulative Carbon Emissions Towards the Trillionth tonne, Nature, Vol. 458, 30 April 2009. ISSN 00280836

Almond, D. P. \& Patel, P. M. (1996). Photothermal Science and Techniques, Chapman \& Hall. ISBN: 0412153300.

Baesso, M. L.;Shen, J.;Snook, R. D.; (1994), Mode-mismatched thermal lens determination of temperature coefficient of optical path length in soda lime glass at different wavelengths, Journal of Applied Physics , 75, 8, 3732 - 3737, ISSN: 0021-8979

Barnwal, B. K. and Sharma, M. P. (2005) Prospects of biodiesel production from vegetable oils in India. Renewable and Sustainable Energy Reviews, 9, pp. 363-378. ISSN 13640321

Bauen, A.; Beal, J.; Parker, R.; Black, M.; Bright, I.; Chalmers, J.; Davidson, P.; Gaines, P.; Gameson, T.; Sustainable Biofuels Prospects and Challenges, Report, The Royal Society, UK, January 2008, ISBN 9780854036622

Bialkowski, S. E. (1996). Photothermal Spectroscopy Methods for Chemical Analysis. John Wiley \& Sons INC., ISBN 0-471-57467-8, Canada

Carslaw, H. S. \& Jaeger, L. C. (1959). Conduction of Heat in Solids, Oxford Clarendon. . ISBN: 0198164599

Castro, M. P. P., Andrade, A. A., Franco, R. A. W., Miranda, P. C. M. L., Sthel, M. S., Vargas, H., Constantino, R., Baesso, M. L. (2005). Thermal properties measurements in biodiesel oils using photothermal techniques, Chem. Phys. Lett. 411: 18-22. ISSN 00092614

Cesar, C. L., Vargas, H., Meyer, J. A. \& Miranda, L. C. M. (1979). Photoacoustic effect in solids, Phys. Rev. Lett. 42 (23): 1570-1573 ISSN 0031-9007 (print) 1079-7114 (online)

Coufal, H. (1984). Photothermal spectroscopy using a pyroelectric thin-film detector, Appl. Phys. Lett. 44 (1): 59.ISSN 00036951

Demirbas, A.; (2003) Biodiesel fuels from vegetable oils via catalytic and non-catalytic supercritical alcohol transesterifications and other methods: a survey. Energy Conversion \& Management. 44 (2003) pp. 2093-2109. ISSN 01968904

Franko, M. (2001) Recent applications of thermal lens spectrometry in food analysis and environmental research Talanta, 54, 1, 30 March 2001, pp.1-13, ISSN 00399140

Glorieux, C., Thoen, J., Bednarz, G., White M. A. \& Geldart, D. J. W. (1995). Photoacoustic investigation of the temperature and magnetic-field dependence of the specific-heat capacity and thermal conductivity near the Curie point of gadolinium, Phys. Rev. B 52 (17): 12770. ISSN 1050-2947 Print; ISSN 1094-1622 Online

Guimarães, A. O., Machado, F. A. L., Zanelato, E. B., Sthel, M. S., da Silva, E. C. \& Aranda, D. A. G.. (2009). Photopyroelectric methodology applied to thermal characterization of biodiesel, International Review of Chemical Engineering 1 (6): 623631 ISSN 20351763

Guimarães, A. O., Soffner, M. E., Mansanares, A. M., Coelho, A. A., Carvalho, A. M. G., Pires, M. J. M., Gama, S. \& da Silva, E. C. (2009). Acoustic detection of the 
magnetocaloric effect: Application to Gd and Gd5.09Ge2.03Si1.88, Phys. Rev. B 80: 134406. ISSN 1050-2947 Print; ISSN 1094-1622 Online

Hansen, J.; Sato, M.; Kharecha, P.; Beerling, D.; Berner, R.; Masson-Delmotte, V. Pagani, M.; Raymo, M.; Royer, D. L. and Zachos, J. C. (2008) Target atmosphere CO2: Where Should Humanity Aim, The Open Atmospherric Science Journal, 2, 217-231, ISSN: 1874-2823

HU, C. e WHINNERY, J. R.; Appl. Opt. 1973, 12, 72. ISSN 0003-6935

IPCC 2007a: Climate Change 2007: The Physical Science Basis. Contribution of Working Group I to the Fourth Assessment Report of the Intergovernmental Panel on Climate Change. Solomon, S., Qin, D., Manning, M., Chen, Z., Marquis, M., Averyt, K. B., Tignor, M. and Miller H. L. (eds.). Cambridge University Press, Cambridge, United Kingdom and New York, NY, USA.

IPCC 2007b: Contribution of Working Group III to the Fourth Assessment Report of the Intergovernmental Panel on Climate Change. Metz, B., Davidson, O. R., Bosch, P. R., Dave, R. and Meyer L. A. (eds) Cambridge University Press, Cambridge, United Kingdom and New York, NY, USA.

Sampaio, J. A.; Lima, S. M.; Catunda, T. ; Medina, A. N.; Bento, A. C. and. Baesso, M. L. (2002) Thermal lens versus DTA measurements for glass transition analysis of fluoride glasses,Journal of Non-Crystalline Solids, Volume 304, Issues 1-3, June 2002, Pages 315-321 ISSN 00223093

Gordon, J. P.; Leite, R. C. C.; Moore, R. S.; Porto, S. P. S. and Whinnery, J. R. (1964) "Long transient effects in lasers with inserted liquids samples," Bull. Am. Phys. Soc. 9, 501. ISSN 00218979.

Gordon, J. P.; Leite, R. C. C.; Moore, R. S.; Porto, S. P. S. and Whinnery, J. R. (1965) "Long transient effects in lasers with lasers with inserted liquid samples," J. Appl. Phys. 36, 3-8.ISSN 00218979.

James Hansen, et al., Target atmosphere CO2: Where Should Humanity Aim, The Open Atmospherric Science Journal, 2, 217-231, (2008) ISSN 18742823

Knothe, G., Gerpen, J.V., Krahl, J. The biodiesel handbook. AOCS PRESS, Urbana, Illinois, 2005. ISSN: 0003-021X

Lima, S. M., Figueiredo, M. S., Andrade, L. H. C., Caíres, A. R. L., Oliveira S. L. \& Aristone, F. (2009). Effects of residue and antioxidant on thermo-optical properties of biodiesel, Applied Optics 48: 5728 - 5732. ISSN 01436228

Meinshausen, M. and Meinshausen, N. (2009) Warning Caused by Cumulative Carbon Emissions Towards the Trillionth tonne, Nature, Vol. 458, 30 April 2009 ISSN 00280836

Meinshausen, M.; Meinshausen, N.; Hare, W.; Raper, S. C. B.; Frieler, K.; Knutti, R.; Frame, D. J. and Allen, M. R. (2009) Greehouse - Gas Emission Targets for Limiting Global Warning to 2 o C. Nature, Vol. 458, 30 April pp.1158-1163. ISSN 00280836

Menon, P.M., Rajesh, R. N. \& Glorieux, C. (2009). High accuracy, self-calibrating photopyroelectric device for the absolute determination of thermal conductivity and thermal effusivity of liquids, Rev. Sci. Instrum. 74 (1): 054904-1. ISSN 0034-6748

Pinto, A. C.; Guarieiro, L. L. N.; Rezende, M. J. C.; Ribeiro, N. M.; Torres, E. A.; Lopes, W. A.; Pereira, P. A. P. and Andrade, J. B. (2005) Biodiesel: An Overview. J. Braz. Chem. Soc., Vol. 16, No. 6B, pp. 1313-1330. ISSN 16784790 
Ragauskas, A. J.; Williams, C. K.; Davison, B. H.; Britovsek, G.; Cairney, J.; Eckert, C. A.; Frederick Jr., W. J.; Hallett, J. P.; Leak, D. J.; Liotta, C. L.; Mielenz, J. R. ; Murphy, R.; Templer, R. and Tschaplinski, T. (2006) The Path Forward for Biofuels and Biomaterials. Science, Vol. 311, 27 January (2006) pp. 484-489. print ISSN 00368075; online ISSN 1095-9203.

Rocha, A. M.; Silva, W. C.; Sangiorgio, L. F. M.; Sthel, M. S.; Andrade, A. A. C.; Aranda, D. A. G. and Castro, D. A. G. (2009) Thermal diffusivity measurements of biodiesel fuel using Thermal Lens Technique. International Review of Chemical Engineering. November 2009,Vol. 1 No 6 pp. 336-639 ISSN 20351763

Rockström, J.; Steffen, W.;Noone, K.; Persson, A.; Chapin , F. S. and Lambin, E. F.; Lenton, T.M.; Scheffer, M. ; Folke, C.; Schellnhuber, H.J.; Nykvist, B.; de Wit, C A. ; Hughes, T.; Leeuw,S. V.; Rodhe, H.; Sörlin, S. ; Snyder, P.K.; Costanza, R.; Svedin, U.; Falkenmark, M. ; Karlberg, L.; Corell, R.W.; Fabry, V.J.; Hansen, J.; Walker, B. ; Liverman, D. ; Richardson, K.; Crutzen, P. and Foley, J.(2009) A safe operating space for humanity, Nature, Vol. 461, 24 September 2009, pp. 472 - 475. ISSN 00280836

Rosencwaig, A. (1973). Theory of the photoacoustic effect with solids, J. Opt. Commun. 7 (305). ISSN 01734911.

Rosenzweig, C.; Karoly, D.; Vicarelli, M., Neofotis, P., Wu, Q.; Casassa, G.; Menzel, A. ; Root, T. L.; Estrella, N; Seguin, B.; Tryjanowski, P.; Liu, C.; Rawlins, S. and Imeson, A. Z. (2008) Attributing physical and biological impacts to antropogenic climate change, Nature, Vol 453, 15 May 2008, pp.353-358. ISSN 00280836

Schuchardt, U.; Sercheli, R. and Vargas, R.M.; (1998) Transesterification of Vegetable Oils: a Review. J. Brazil. Chem. Soc. Vol. 9, N0 1, pp. 199-210 ISSN 0103-5053 printed version. ISSN 1678-4790 online version.

Shen, J., Lowe, R. D., Snook, R. D. (1992). A model for cw laser induced mode-mismatched dual-beam thermal lens spectrometry, Chemical Physics, 165 (1-2): 385-396. ISSN 03010104

Solomon, S.; Plattner, G.; Knutti, R. and Friedlingstein, P. (2009) Irreversible climate change due to carbon dioxide emissions, PNAS, Vol. 106, no. 6, 10 February 2009,pp. 17041709. ISSN 1091-6490

Steffen, W.; Sanderson, A.; Tyson, P. D.; Jäger, J.; Matson, P. A.; Moore, B.; Oldfield, F.; Richardson, K.; Schellnhuber H. J.; Turner, B. L. and Wasson R. J. (2003) Global Change and the Earth System: A Planet under Pressure, Springer - Verlag, Editors: Steffen, W.; Eliott, S. and Bellamy, J., pp.1-41. published by Springer-Verlag Berlin Heidelberg New York.. ISBN 91-631-5380-7, New York.

Tilman, D.; Hill, J. and Lehman, C. (2006) Carbon-Negative Biofuels from Low-Input HighDiversity Grassland Biomass. Science, Vol. 314, 8 December 2006 ISSN 09320776

Vargas, H. \& Miranda, L. C. (1988). Photoacoustic and related photothermal techniques, Phys. Rep. 161 (2): 43-101. ISSN 03701573 


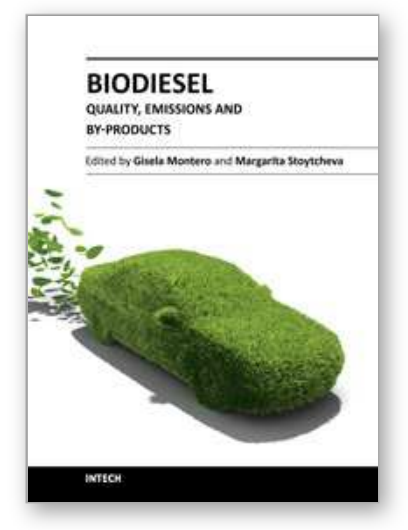

\author{
Biodiesel- Quality, Emissions and By-Products \\ Edited by Dr. Gisela Montero
}

ISBN 978-953-307-784-0

Hard cover, 380 pages

Publisher InTech

Published online 16, November, 2011

Published in print edition November, 2011

This book entitled "Biodiesel: Quality, Emissions and By-products" covers topics related to biodiesel quality, performance of combustion engines that use biodiesel and the emissions they generate. New routes to determinate biodiesel properties are proposed and the process how the raw material source, impurities and production practices can affect the quality of the biodiesel is analyzed. In relation to the utilization of biofuel, the performance of combustion engines fuelled by biodiesel and biodiesels blends are evaluated. The applications of glycerol, a byproduct of the biodiesel production process as a feedstock for biotechnological processes, and a key compound of the biorefinery of the future is also emphasized.

\title{
How to reference
}

In order to correctly reference this scholarly work, feel free to copy and paste the following:

Maria Castro, Francisco Machado, Aline Rocha, Victor Perez, André Guimarães, Marcelo Sthel, Edson Corrêa and Helion Vargas (2011). Characterization of Biodiesel by Unconventional Methods: Photothermal Techniques, Biodiesel- Quality, Emissions and By-Products, Dr. Gisela Montero (Ed.), ISBN: 978-953-307-7840, InTech, Available from: http://www.intechopen.com/books/biodiesel-quality-emissions-and-byproducts/characterization-of-biodiesel-by-unconventional-methods-photothermal-techniques

\section{INTECH}

open science | open minds

\section{InTech Europe}

University Campus STeP Ri

Slavka Krautzeka 83/A

51000 Rijeka, Croatia

Phone: +385 (51) 770447

Fax: +385 (51) 686166

www.intechopen.com

\section{InTech China}

Unit 405, Office Block, Hotel Equatorial Shanghai

No.65, Yan An Road (West), Shanghai, 200040, China

中国上海市延安西路65号上海国际贵都大饭店办公楼 405 单元

Phone: +86-21-62489820

Fax: +86-21-62489821 
(C) 2011 The Author(s). Licensee IntechOpen. This is an open access article distributed under the terms of the Creative Commons Attribution 3.0 License, which permits unrestricted use, distribution, and reproduction in any medium, provided the original work is properly cited. 